\title{
Fungal loop transfer of nitrogen depends on biocrust constituents and nitrogen form
}

\author{
Zachary T. Aanderud ${ }^{1}$, Trevor B. Smart ${ }^{1}$, Nan Wu ${ }^{2}$, Alexander S. Taylor ${ }^{1}$, Yuanming Zhang ${ }^{2}$, and Jayne Belnap ${ }^{3}$ \\ ${ }^{1}$ Department of Plant and Wildlife Sciences, Brigham Young University, Provo, UT 84602, USA \\ ${ }^{2}$ Xinjiang Institute of Ecology and Geography, Key Laboratory of Biogeography and Bioresource in Arid Land, \\ Chinese Academy of Sciences, Urumqi 830011, China \\ ${ }^{3}$ US Geological Survey, Southwest Biological Science Center, 2290 SW Resource Blvd., Moab, UT 84532, USA
}

Correspondence: Zachary T. Aanderud (zachary_aanderud@byu.edu)

Received: 15 October 2017 - Discussion started: 20 November 2017

Revised: 17 May 2018 - Accepted: 26 May 2018 - Published: 22 June 2018

\begin{abstract}
Besides performing multiple ecosystem services individually and collectively, biocrust constituents may also create biological networks connecting spatially and temporally distinct processes. In the fungal loop hypothesis rainfall variability allows fungi to act as conduits and reservoirs, translocating resources between soils and host plants. To evaluate the extent to which biocrust species composition and nitrogen $(\mathrm{N})$ form influence loops, we created a minor, localized rainfall event containing ${ }^{15} \mathrm{NH}_{4}^{+}$and ${ }^{15} \mathrm{NO}_{3}^{-}$. We then measured the resulting $\delta^{15} \mathrm{~N}$ in the surrounding dry cyanobacteria- and lichen-dominated crusts and grass, Achnatherum hymenoides, after $24 \mathrm{~h}$. We also estimated the biomass of fungal constituents using quantitative PCR and characterized fungal communities by sequencing the $18 \mathrm{~S}$ rRNA gene. We found evidence for the initiation of fungal loops in cyanobacteria-dominated crusts where ${ }^{15} \mathrm{~N}$, from ${ }^{15} \mathrm{NH}_{4}^{+}$, moved $40 \mathrm{~mm} \mathrm{~h}^{-1}$ in biocrust soils with the $\delta^{15} \mathrm{~N}$ of crusts decreasing as the radial distance from the water addition increased (linear mixed effects model (LMEM)): $R^{2}=$ $\left.0.67, F_{2,12}=11, P=0.002\right)$. In cyanobacteria crusts, $\delta^{15} \mathrm{~N}$, from ${ }^{15} \mathrm{NH}_{4}^{+}$, was diluted as Ascomycota biomass increased (LMEM: $R^{2}=0.63, F_{2,8}=6.8, P=0.02$ ), Ascomycota accounted for $82 \%( \pm 2.8)$ of all fungal sequences, and one order, Pleosporales, comprised $66 \%( \pm 6.9)$ of Ascomycota. The seeming lack of loops in moss-dominated crusts may stem from the relatively large moss biomass effectively absorbing and holding $\mathrm{N}$ from our minor wet deposition event. The substantial movement of ${ }^{15} \mathrm{NH}_{4}^{+}$may indicate a fungal preference for the reduced $\mathrm{N}$ form during amino acid transformation and translocation. We found a marginally signifi-
\end{abstract}

cant enrichment of $\delta^{15} \mathrm{~N}$ in A. hymenoides leaves but only in cyanobacteria biocrusts translocating ${ }^{15} \mathrm{~N}$, offering evidence of links between biocrust constituents and higher plants. Our results suggest that minor rainfall events may initiate fungal loops potentially allowing constituents, like dark septate Pleosporales, to rapidly translocate $\mathrm{N}$ from $\mathrm{NH}_{4}^{+}$over $\mathrm{NO}_{3}^{-}$ through biocrust networks.

\section{Introduction}

Fungi may act as conduits for biological networks, connecting belowground ecosystem processes to plants. Soil fungi contribute to all aspects of litter decomposition via the following: the generation of a myriad of extracellular enzymes (Osono, 2007; Schneider et al., 2012); altered trophic dynamics, decomposer species diversity, and nutrient turnover rates (Hattenschwiler et al., 2005); and by forming multiple types of endophyte-plant symbioses (Johnson et al., 1997; Saikkonen et al., 2004). Endophytic fungi, in particular, form hubs connecting spatially and temporally distinct microbialmediated soil processes and plants. For example, the pervasive distribution of mycorrhizae in mesic systems allows common mycorrhizal networks to deliver essential resources. Therefore, mycorrhizae promote or hinder seedling growth depending on the network species composition (van der Heijden and Horton, 2009), and facilitate the one-way transfer of multiple forms of nitrogen $(\mathrm{N})$ and phosphorus $(\mathrm{P})$ between two plant species linked by arbuscular mycorrhizae and ectomycorrhizae (He et al., 2003; Walder et al., 2012). In 
xeric systems, endophytic fungi are also implicated in moving resources within biological networks in a theory known as the fungal loop hypothesis. The hypothesis states that fungi, supported by biotrophic carbon (C) from plants and terrestrial cyanobacteria, act as intermediate reservoirs transforming and translocating resources between soils and plants (Collins et al., 2008, 2014). Perhaps the most notable example of a fungal loop, albeit from a limited number of studies, occurred in fungal-dominated cyanobacteria biocrusts from a Chihuahuan Desert grassland. Specifically, ${ }^{15} \mathrm{NO}_{3}^{-}$applied to a root-free biocrust rapidly moved into the perennial grass, Bouteloua sp., up to $1 \mathrm{~m}$ away within $24 \mathrm{~h}$ (Green et al., 2008). Furthermore, ${ }^{13} \mathrm{C}$-labeled glutamic acid applied to the leaf surfaces of Bouteloua was found in biocrusts. Despite the intriguing evidence, many aspects of this burgeoning hypothesis remain to be validated (Collins et al., 2014).

Biocrust composition and soil moisture availability interactions may dictate the movement of resources in fungal loops. Desert fungal-plant interactions occur across spatially discontinuous patches of vegetation interspersed by patches of soils colonized by biocrusts (Belnap et al., 2005). Fungi participating in loops are necessarily associated with a mosaic of other biocrust organisms (i.e., cyanobacteria, green algae, lichens, mosses, and other bacteria). The metabolic activity of biocrust constituents participating in fungal loops, including plants, are moisture-dependent and regulated by the magnitude and seasonality of episodic rainfall events. A pulse-reserve paradigm (Collins et al., 2008) may explain biological activities where minor rainfall pulses stimulate microorganisms, generating reserves of resources to be exploited during subsequent rainfall events (Huxman et al., 2004; Welter et al., 2005). In such loops, minor rainfall events may stimulate $\mathrm{N}_{2}$ fixation by free or lichen-associated cyanobacteria (Belnap et al., 2003), $\mathrm{N}$ mineralization by bacteria and fungi (Cable and Huxman, 2004; Yahdjian and Sala, 2010), and nitrification and possibly denitrification (Wang et al., 2014), potentially altering levels of $\mathrm{NH}_{4}^{+}$or $\mathrm{NO}_{3}^{-}$. Fungal species, including fungal endophytes, may compete with mosses, lichen, cyanobacteria, and other bacteria for newly released $\mathrm{N}$. Once sequestered, the $\mathrm{N}$ may be transformed into amino acids and transported within mycelium (Jin et al., 2012; Behie and Bidochka, 2014). Larger rainfall events may then activate plants, allowing the host plant to receive $\mathrm{N}$ from the fungi and transfer photosynthate to the fungal endophyte. If fungal endophytes are poor competitors for newly released $\mathrm{N}$, preferentially sequester one inorganic $\mathrm{N}$ form over another, or more efficiently transform and transport $\mathrm{NH}_{4}^{+}$rather than $\mathrm{NO}_{3}^{-}$, biocrust constituents and $\mathrm{N}$ form may influence the translocation of $\mathrm{N}$ in fungal loops.

The fungal endophytes most likely involved in the loop hypothesis are dark septate fungi. Few arbuscular mycorrhizal fungi are found in biocrusts (Porras-Alfaro et al., 2011) or as endophytes in desert plants (Titus et al., 2002), due to mycorrhizae being relatively sensitive to dry soil conditions (Aguilera et al., 2016). In contrast, the majority of biocrust fungi are Ascomycota, with the Pleosporales being widespread and dominant (Bates et al., 2012; Porras-Alfaro et al., 2011). Pleosporales, along with other Ascomycota fungal orders, contain dark septate endophytes (Jumpponen and Trappe, 1998). Dark septate endophytes are thermal- and droughttolerant fungi due to melanin-rich cell walls conferring protection from UV and drought stress (Gostincar et al., 2010). Taken together, the prevalence of dark septate fungi in desert systems, along with their ability to maintain metabolic activity under low water potentials (Barrow, 2003), makes these endophytes excellent candidates to translocate resources in loops (Green et al., 2008).

Minor rainfall events may allow fungi to act as conduits and reservoirs for $\mathrm{N}$. To investigate the potential for biocrust constituents and $\mathrm{N}$ form to influence the movement of $\mathrm{N}$ through the putative fungal loops, we created minor, localized rainfall events. We then measured $\delta^{15} \mathrm{~N}$, from ${ }^{15} \mathrm{~N}-\mathrm{NH}_{4}^{+}$ and ${ }^{15} \mathrm{~N}_{-} \mathrm{NO}_{3}^{-}$, within the surrounding dry cyanobacteriaand moss-dominated crusts, and grass, Achnatherum hymenoides (Indian ricegrass). In tandem with ${ }^{15} \mathrm{~N}$ analyses, we estimated the biomass of two major divisions of fungi (Ascomycota and Basidiomycota) and bacteria, and characterized fungal communities by sequencing the 18S rRNA gene to identify potential links between fungal taxa and ${ }^{15} \mathrm{~N}$ movement.

\section{Materials and methods}

\subsection{Site description}

We conducted our study in two cold desert ecosystems of the Colorado Plateau, UT. One site was near Castle Valley $\left(40^{\circ} 05^{\prime} 27.43^{\prime \prime} \mathrm{N}-112^{\circ} 18^{\prime} 18.24^{\prime \prime} \mathrm{W}\right)$ and the other was adjacent to the US Geological Survey (USGS) Southwest Biological Science Center Research Station in Moab, UT $\left(40^{\circ} 05^{\prime} 27.43^{\prime \prime} \mathrm{N}-112^{\circ} 18^{\prime} 18.24^{\prime \prime} \mathrm{W}\right)$. Rugose crusts consisting of $22 \%$ moss Syntrichia caninervis, 5-7\% cyanolichens Collema tenax , and Collema coccophorum and $55 \%$ cyanobacteria cover the Castle Valley site (Darrouzet-Nardi et al., 2015), while smooth, light algal crusts dominated by one cyanobacterium, Microcoleus vaginatus, cover the USGS site. Across both sites, vegetation is dominated by the perennial grass Achnatherum hymenoides (Roem \& Schult) and the native perennial shrub Atriplex confertifolia (Torr. \& Frém). Mean annual temperature and precipitation at Castle Valley are $13^{\circ} \mathrm{C}$ and $269 \mathrm{~mm}$, respectively, while the USGS site is slightly warmer (MAT $=13.8^{\circ} \mathrm{C}$ ) and drier (MAP = 189 mm; based on 1981-2010 data; WRCC, 2017). Both soils are Aridisols with Castle Valley classified as a sandy loam, calcareous Rizno series (Darrouzet-Nardi et al., 2015) and USGS as a Bluechief series sandy loam. 


\subsection{Simulated rainfall events and ${ }^{15} \mathrm{~N}$ form applications}

We simulated minor, localized rainfall events and measured $\delta^{15} \mathrm{~N}$, from ${ }^{15} \mathrm{~N}-\mathrm{NH}_{4}^{+}$and ${ }^{15} \mathrm{~N}-\mathrm{NO}_{3}^{-}$rainfall events containing two isotopically-labeled, inorganic $\mathrm{N}$ forms. We then tracked the movement of the label through our mossdominated (Castle Valley) and cyanobacteria-dominated biocrusts (USGS station), and A. hymenoides. First, we randomly selected six circular plots per site; the sites had a radius of $1.0 \mathrm{~m}$ and were at least $10 \mathrm{~m}$ apart from each other. Three plots were assigned to be labeled with $\mathrm{K}^{15} \mathrm{NO}_{3}$ (99 atom\%) and the other three plots to be labeled with $\left({ }^{15} \mathrm{NH}_{4}\right)_{2} \mathrm{SO}_{4}$ (99 atom \%). Second, we randomly selected five biocrust patches and five $A$. hymenoides along eight axes (e.g., N, NE, E, SE, S, SW, W, and NW) radiating from the center of each circular plot and measured the radial distance to biocrusts or grasses (see Fig. 1 in the Supplement for an example of the circular plot set-up). Third, we simulated a $2.5 \mathrm{~mm}$ rainfall event by spraying $3 \mathrm{~mL}$ of deionized water solution and either isotopic label $\left(0.30 \mathrm{mg}{ }^{15} \mathrm{~N}\right)$ onto a $5 \mathrm{~cm}$ diameter circle in the center of the circular plots $(2$ biocrust types $\times 3$ circular plots locations $\times 2 \mathrm{~N}$ forms $\times \approx 10$ samples [4-5 biocrusts or 4-7 A. hymenoides depending on grass density in the circular plot $]=137$ ). For the isotopic applications, either $2.60 \mathrm{~g}$ of 99 atom $\% \mathrm{~K}^{15} \mathrm{NO}_{3}$ or $1.70 \mathrm{~g}$ of 99 atom $\%\left({ }^{15} \mathrm{NH}_{4}\right)_{2} \mathrm{SO}_{4}$ was dissolved in $18 \mathrm{~mL}$ of deionized water to create a 1.43 or $0.72 \mathrm{M}$ solution, respectively. The ${ }^{15} \mathrm{~N}$ additions wetted the sandy loams (bulk density $\approx 1.5 \mathrm{~g} \mathrm{~cm}^{-3}$ ) to a depth of $1 \mathrm{~cm}$ and added approximately equal $\mathrm{NH}_{4}^{+}\left(10 \mu \mathrm{g} \mathrm{Ng}\right.$ soil $\left.{ }^{-1}\right)$ and double $\mathrm{NO}_{3}^{-}$concentrations to surface soils (Sperry et al., 2006). All additions were completed at midday in April, as A. hymenoides were starting to set seed.

\subsection{Sample collection and ${ }^{15} \mathrm{~N}$ analyses}

Biocrust and foliage samples were collected $24 \mathrm{~h}$ after the simulated rainfall event containing our different inorganic ${ }^{15} \mathrm{~N}$ forms. Biocrusts were removed as three subsamples from each biocrust location with a soil corer $(2 \mathrm{~cm}$ diameter $\times 5 \mathrm{~cm}$ length) to a depth of $2 \mathrm{~mm}$. Crust distances away from the tracer application ranged from 22 to $97 \mathrm{~cm}$. The composited soil samples were kept cold $\left(5^{\circ} \mathrm{C}\right)$ in the field, split in the lab, and a portion of the soil was frozen $\left(-20^{\circ} \mathrm{C}\right)$ until fungal and bacterial DNA analyses were performed. We randomly selected five leaves from the chosenAchnatherum species, which ranged in distance anywhere from 29 to $120 \mathrm{~cm}$ away from the tracer application and in volume from 0.002 to $0.048 \mathrm{~m}^{3}$. The leaves and remaining soils (sieved $2 \mathrm{~mm}$ ) were air-dried, ground in a reciprocating tissue homogenizer, and analyzed for ${ }^{15} \mathrm{~N}$ using a PDZ Europa ANCA GSL elemental analyzer, interfaced with a PDZ Europa 2020 isotope ratio mass spectrometer (Sercon Ltd., Cheshire, UK) at the University of California Davis Stable Isotope Facility (http://stableisotopefacility.ucdavis.edu, last access:
January 2016). We expressed the resulting isotope ratios in $\delta$ notation as parts per thousand (\%o):

$\delta^{15} \mathrm{~N}=\left(R_{\text {sample }} / R_{\text {standard }}\right) \times 1000$,

where $R$ is the molar ratio of the heavier to the lighter isotope $\left({ }^{15} \mathrm{~N} /{ }^{14} \mathrm{~N}\right)$ for the standard or sample. To track the movement of inorganic $\mathrm{N}$ forms through our two biocrust types (moss-lichen-dominated and cyanobacteria-dominated biocrust) and into grasses, we analyzed the relationships between $\delta^{15} \mathrm{~N}$ present in crust and leaf tissue to the distance of the crust and Achnatherum grass by site. This was undertaken by creating linear mixed effects models for the biocrust type and $\mathrm{N}$ form combinations. In all models, distances of biocrusts or grasses were nested within individual circular plots, and the three plots were treated as a random factor to control for the impact of plot differences on our response variable. All models were created with the $1 \mathrm{~m}$ function in $R$ (R Development Core Team, 2017).

\subsection{Biomass estimations of major fungal components}

To investigate the potential for fungi to translocate our ${ }^{15} \mathrm{~N}$ forms, we estimated the biomass of two major divisions of fungi (Ascomycota and Basidiomycota) and bacteria in biocrusts using quantitative PCR. From the frozen biocrust samples, we extracted genomic DNA using a DNeasy PowerLyzer PowerSoil Kit (Qiagen, MD, USA) and quantified the gene copy numbers of Ascomycota and Basidiomycota on a Mastercycler ep realplex qPCR (Eppendorf, Hamburg, Germany) with SYBR Green. We amplified division-specific regions of the internal transcribed spacer (ITS) with primer pair ITS5 (forward) and ITS4A (reverse) for Ascomycota (Larena et al., 1999) and ITS4B (forward) and $5.8 \mathrm{sr}$ (reverse) for Basidiomycota (Fierer et al., 2005). We selected the universal bacterial 16S rRNA primer set EUB338 (forward) and Eub518 (reverse) to estimate the biomass of bacteria (Aanderud et al., 2013). In $12.5 \mu \mathrm{L}$ reactions, using KAPA2G Robust PCR Kits (KAPA Biosystems, Wilmington, MA, USA), we amplified targeted genes using the following thermocycler condition: an initial denaturation step at $94^{\circ} \mathrm{C}$ for 3 min followed by 35 cycles of denaturation at $94^{\circ} \mathrm{C}$ for $45 \mathrm{~s}$; annealing at either at $55^{\circ} \mathrm{C}$ (Ascomycota), $64^{\circ} \mathrm{C}$ (Basidiomycota), or $60^{\circ} \mathrm{C}$ (bacteria) for $30 \mathrm{~s}$; and extension at $72^{\circ} \mathrm{C}$ for $90 \mathrm{~s}$. We generated qPCR standards for Basidiomycota, Ascomycota, and bacteria from biocrusts using the TOPO TA Cloning ${ }^{\circledR}$ kit (ThermoFisher Scientific, MA, USA) as outlined by Aanderud et al. (2013). The coefficients of determination $\left(R^{2}\right)$ for our assays ranged from 0.90 to 0.99 , and amplification efficiencies fell between 0.99 and 1.92. We analyzed the relationships between biocrust $\delta^{15} \mathrm{~N}$ and the gene copy number of Ascomycota, Basidiomycota, and bacteria by creating linear mixed effects models for each biocrust type and $\mathrm{N}$ form combination ( 2 biocrust types $\times 3$ circular plots locations $\times 2 \mathrm{~N}$ forms $\times \approx 1-5$ biocrusts $=48$ ). 
DNA from eight moss-dominated and four cyanobacteriadominated biocrusts were difficult to amplify, especially one moss biocrust circular plot, reducing the number of replicates from five to one. We used the $1 m$ function in $R$ and treated plot as a random factor and gene copy number nested within plot. We further tested for differences in our biomass estimates between the crust types using multiple $t$ tests and a Benjamini-Hochberg correction to control for the false discovery rate associated with multiple comparisons (Benjamini and Hochberg, 1995).

\subsection{Biocrust fungal communities}

To identify the fungal taxa participating in $\mathrm{N}$ translocation, we characterized fungal communities in biocrusts using bar-coded sequencing. We PCR amplified the V9 region of the 18S rRNA gene using a universal eukaryote primer set, $1391 \mathrm{~F}$ and EukBr, with a unique $12 \mathrm{bp}$ Golay barcode fused to EukBr (Amaral-Zettler et al., 2009; Hamady et al., 2008). Thermocycler parameters were similar to qPCR analyses and consisted of a denaturation step at $94{ }^{\circ} \mathrm{C}$ for $3 \mathrm{~min}$, followed by 35 cycles of denaturation at $94^{\circ} \mathrm{C}$ for $45 \mathrm{~s}$, an annealing step at $57^{\circ} \mathrm{C}$ for $60 \mathrm{~s}$, elongation at $72{ }^{\circ} \mathrm{C}$ for $90 \mathrm{~s}$, and a final extension at $72^{\circ} \mathrm{C}$ for $10 \mathrm{~min}$. We then purified and pooled PCR amplicon libraries to near equimolar concentrations using SequalPrep ${ }^{\mathrm{N}}$ ormalization Plate Kits (Invitrogen, Carlsbad, CA, USA) and quantified the amplicon libraries by realtime qPCR using a KAPA Library Quantification Kit (Kapa Biosystems, Wilmington, MA, USA). All samples were sequenced at the Brigham Young University DNA Sequencing Center (http://dnasc.byu.edu/, last access: July 2017) using the Illumina HiSeq 2500 platform (Illumina Biotechnology, San Diego, CA, USA), generating $2 \times 250$ paired-end reads. Illumina sequence reads were analyzed within QIIME (v. 1.9.1), an open-source software pipeline suitable for microbial community analysis (Caporaso et al., 2010). We removed barcodes and primers with a custom, in-house script previous to joining paired-end reads by using fastq-join under default parameters (Aronesty, 2011). Joined reads were then de-multiplexed and checked for chimeras (Haas et al., 2011). We then clustered the de-multiplexed reads into operational taxonomic units (OTUs), applying a similarity threshold of $97 \%$ and using QIIME's default OTU clustering tool - uclust (Edgar et al., 2011). Taxonomies of representative OTUs were assigned using uclust and the 18S rRNA gene SILVA 128 database which was clustered into OTUs at $97 \%$ similarity (Quast et al., 2013). To evaluate if biocrust type supported similar fungal composition, we calculated the relative recovery of 27 fungal orders, including dark septate lineages. We tested for differences between biocrust types using $t$ tests and a Benjamini-Hochberg correction (2 biocrust types $\times 6$ randomly selected biocrusts $=12$ ).

\section{Results}

\subsection{Translocation of ${ }^{15} \mathrm{NH}_{4}^{+}$in cyanobacteria biocrusts}

The movement of ${ }^{15} \mathrm{~N}$ was clearly apparent in cyanobacteriadominated biocrusts following the addition of ${ }^{15} \mathrm{NH}_{4}^{+}$, with $\delta^{15} \mathrm{~N}$ decreasing as the radial distance from the central application point of ${ }^{15} \mathrm{NH}_{4}^{+}$increased. In the overall model

$\delta^{15} \mathrm{~N}$ biocrust $=51-0.71($ distance $)+0.06($ distance $\times$ plot $)$,

$\left(R^{2}=0.67, F_{2,12}=11, P=0.002\right.$, Fig. 1a), distance was significant $(P=0.003)$ and possessed a negative slope. Surrounding the tracer application, $\delta^{15} \mathrm{~N}$ was enriched upwards of $40 \%$ more than $20 \mathrm{~cm}$ away and continued to be enriched to approximately $10 \%$ almost $100 \mathrm{~cm}$ away with enrichment ranging from 9.1 to $49 \%$. There was no such relationship between $\delta^{15} \mathrm{~N}$ and the radial distance from any other crust type or $\mathrm{N}$ form as demonstrated by the mixed effect models (cyanobacteria biocrust ${ }^{15} \mathrm{NO}_{3}^{-}$addition: $R^{2}=0.17$, $F_{2,12}=1.2, P=0.32$, Fig. $1 \mathrm{~b}$; moss biocrust ${ }^{15} \mathrm{NH}_{4}^{+}$addition: $R^{2}=0.01, F_{2,12}=0.07, P=0.94$, Fig. $1 \mathrm{a}$; and moss biocrust ${ }^{15} \mathrm{NO}_{3}^{-}$addition: $R^{2}=0.16, F_{2,12}=1.2, \mathrm{P}=0.33$, Fig. 1b). The location of the three circular plots was not a significant factor in any linear mixed effects models for biocrusts.

\subsection{Potential movement of ${ }^{15} \mathrm{NH}_{4}^{+}$into grass leaves in cyanobacteria biocrusts}

None of the label appeared to reach A. hymenoides leaves in either of the two types of biocrusts. However, in cyanobacteria-dominated biocrusts where ${ }^{15} \mathrm{~N}$ from ${ }^{15} \mathrm{NH}_{4}^{+}$ was translocated, the mixed effects model relating $\delta^{15} \mathrm{~N}$ from ${ }^{15} \mathrm{NH}_{4}^{+}$to $A$. hymenoides leaves was significant $\left(R^{2}=0.37\right.$, $\left.F_{2,17}=5.1, P=0.02\right)$ :

$\delta^{15} \mathrm{~N}$ leaves $=3.1-0.03($ distance $)+0.01($ distance $\times$ plot $)$

and the radial distance was marginally significant $(P=0.08$, data not shown). The $\delta^{15} \mathrm{~N}$ in leaves declined the further away the grass was from the ${ }^{15} \mathrm{~N}$ application point, with leaf enrichment between 1.0 and $6.7 \%$. In the other three models, the $R^{2}, F$ values, and $P$ values of all other mixed effects models ranged from 0.06 to $0.10,0.46$ to 0.67 , and 0.54 to 0.64 , respectively (data not shown). The $\delta^{15} \mathrm{~N}$ found in $A$. hymenoides leaves was $2.6 \% \circ \pm 0.45$ (mean \pm SEM) in cyanobacteria biocrusts exposed to ${ }^{15} \mathrm{NO}_{3}^{-}$and $0.85 \% \circ \pm 0.47$ in moss biocrusts. 


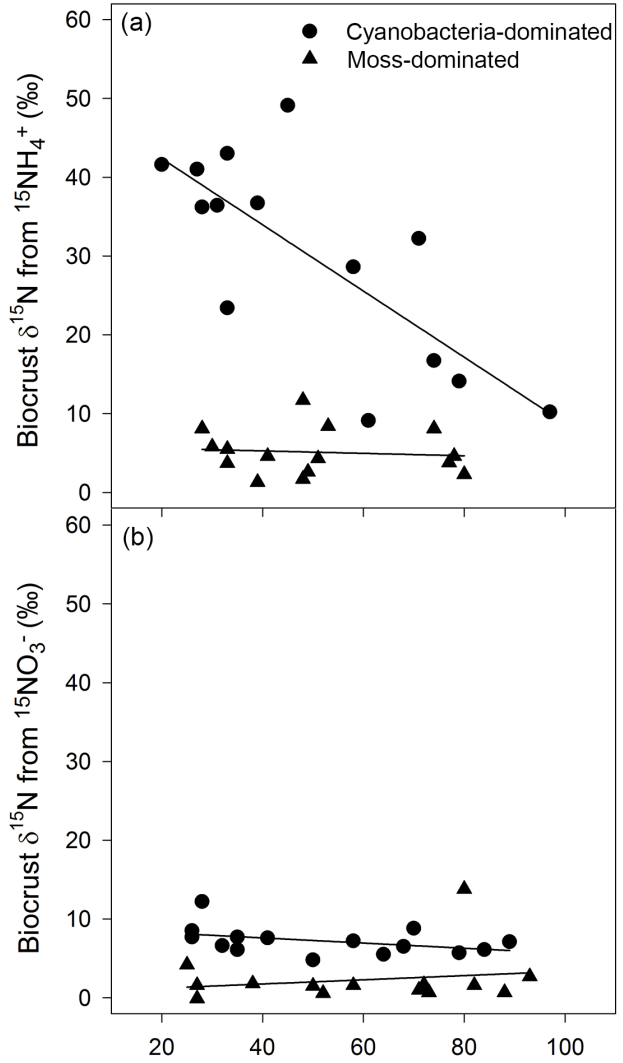

Radial distance from isotope application $(\mathrm{cm})$

Figure 1. Cyanobacteria biocrusts facilitated the translocation of $\mathrm{N}$ from ${ }^{15} \mathrm{NH}_{4}^{+}$in $24 \mathrm{~h}$. Based on linear mixed effects models, $\delta^{15} \mathrm{~N}$, from ${ }^{15} \mathrm{NH}_{4}^{+},\left(R^{2}=0.67, F_{2,12}=11, P=0.002\right)$, decreased as the radial distance from the isotopic application increased (a). There was no such relationship between $\delta^{15} \mathrm{~N}$ and the radial distance from any other crust type or $\mathrm{N}$ form $(\mathbf{a}, \mathbf{b})$. Values are $\delta^{15} \mathrm{~N}(\%)$ from two biocrust types, cyanobacteria- and moss-dominated crusts, across circular plots (radius of $1.0 \mathrm{~m})$ with a central application $(5 \mathrm{~cm}$ diameter circle) of ${ }^{15} \mathrm{NH}_{4}^{+}$or ${ }^{15} \mathrm{NO}_{3}^{-}$in a simulated, minor rainfall event.

\section{3 ${ }^{15} \mathrm{NH}_{4}^{+}$movement in cyanobacteria biocrusts related to Ascomycota}

The biocrust that translocated $\mathrm{N}$ also exhibited a robust relationship between the proxy for Ascomycota biomass and biocrust $\delta^{15} \mathrm{~N}$. In cyanobacteria biocrusts, the greater the gene copy number of Ascomycota the lower the $\delta^{15} \mathrm{~N}$ from ${ }^{15} \mathrm{NH}_{4}^{+}$. In the overall model

$$
\begin{aligned}
\delta^{15} \mathrm{~N} & =280-37(\text { gene copy number Ascomycota) } \\
& +1.1(\text { distance } \times \text { plot })
\end{aligned}
$$

$\left(R^{2}=0.63, F_{2,8}=6.8, P=0.02\right.$, Fig. $\left.2 \mathrm{a}\right)$, the proxy for Ascomycota biomass was significant $(P=0.01)$ and negatively related to $\delta^{15} \mathrm{~N}$. However, in cyanobacteria crusts

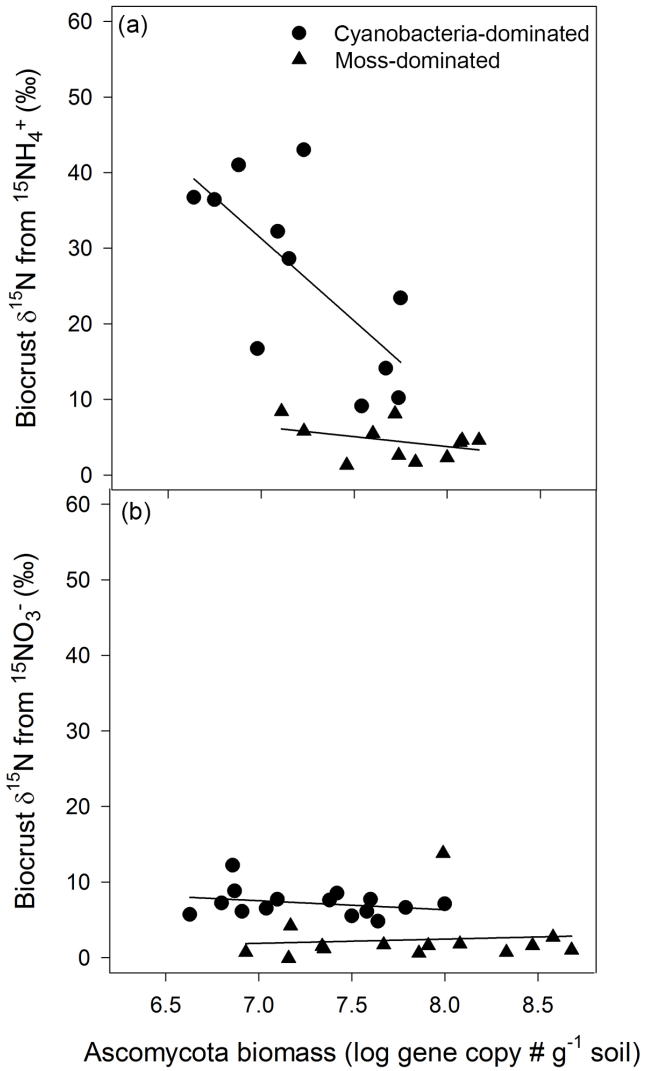

Figure 2. Ascomycota biomass influenced the distance $\mathrm{N}$ traveled. In cyanobacteria crusts, $\delta^{15} \mathrm{~N}$, from ${ }^{15} \mathrm{NH}_{4}^{+}$, was diluted as the Ascomycota gene copy number increased $\left(R^{2}=0.63, F_{2,8}=6.8\right.$, $P=0.02)(\mathbf{a})$. A similar pattern was not apparent in any other crust type or $\mathrm{N}$ form (a, b). Values are $\delta^{15} \mathrm{~N}(\% \circ)$ from biocrusts and Ascomycota gene copy numbers, an approximation of biomass, from qPCR of the ITS region with primer pair ITS5 and ITS4A.

exposed to ${ }^{15} \mathrm{NO}_{3}^{-}$, and in the moss-dominated crusts there was no such relationship between $\delta^{15} \mathrm{~N}$ from ${ }^{15} \mathrm{NO}_{3}^{-}$ and Ascomycota gene copy number (cyanobacteria crust model: $R^{2}=0.08, F_{2,12}=0.6, P=0.58$, Fig. $2 \mathrm{~b}$; moss crust model: $R^{2}=0.16, F_{2,12}=1.2, P=0.33$, Fig. $2 \mathrm{~b}$ ) or in moss crusts exposed to ${ }^{15} \mathrm{NH}_{4}^{+}$additions $\left(R^{2}=0.01\right.$, $F_{2,12}=0.07, P=0.94$, Fig. 2a). Basidiomycota and bacteria biomass in both crust types was not related to either $\mathrm{N}$ form (data not shown). The biomass estimates of all measured biocrust components were consistently higher in moss- than cyanobacteria-dominated crusts. Basidiomycota biomass was $1.5 \times 10^{9} \pm 5.5 \times 10^{8}$ in cyanobacteria and $5.8 \times 10^{9} \pm 7.2 \times 10^{8}$ in moss biocrusts ( $t$ test, $t=4.5, \quad P<0.0001, \mathrm{~d} f=1$, data not shown). Ascomycota biomass was $2.6 \times 10^{7} \pm 4.5 \times 10^{6}$ in cyanobacteria and $1.1 \times 10^{8} \pm 2.4 \times 10^{7}$ in moss biocrusts ( $t$ test, $t=3.3, \quad P=0.003, \mathrm{~d} f=1)$. Bacterial biomass was at least two orders of magnitude lower in cyanobacteria biocrusts $\left(\right.$ cyanobacteria $=5.5 \times 10^{6} \pm 8.9 \times 10^{5}$ and moss 
crusts $=2.7 \times 10^{7} \pm 4.8 \times 10^{6},(t$ test, $t=4.5, P<0.0001$, $\mathrm{d} f=1)$.

\subsection{Dark septate fungi as major components of biocrusts}

Four of the nine fungal orders, known to contain dark septate endophyte members, were present in both biocrust types, with the Pleosporales and Pezizales being the dominant taxa. In biocrusts, fungi comprised much of the eukaryotic community (cyanobacteria $=30 \% \pm 4.7$ and moss $=33 \% \pm 4.0$ ), Ascomycota was the most common fungal division (cyanobacteria $=82 \% \pm 2.8$ and moss $=87 \% \pm 2.9$ ), and orders with known dark septate members accounted for at least $67 \%$ of the Ascomycota (cyanobacteria $=83 \% \pm 4.8$ and moss $=67 \% \pm 8.6$, Fig. 3). In cyanobacteria biocrusts, Pleosporales accounted for $66 \%( \pm 6.9)$ of all dark septates and the recovery of this taxa was twice as high in cyanobacteria- as in moss- dominated crusts ( $t$ test, $t=03.0, P=0.01, \mathrm{~d} f=1)$. Even though the relative abundance of Pleosporales differed, the number of gene copies of Pleosporales was similar between the two biocrusts (cyanobacteria $=1.7 \times 10^{7} \pm 6.3 \times 10^{6}$ and moss $=2.9 \times 10^{7} \pm 1.3 \times 10^{7}, t$ test, $t=0.99, P=0.35$, $\mathrm{d} f=1)$ as determined by an extrapolation of qPCR values in conjunction with percent recovery of taxa for Ascomycota. Pezizales comprised a relatively large percentage of the biocrust community in moss-dominated biocrust with a recovery of $15( \pm 8.3)$ and $28 \%( \pm 9.0)$ in cyanobacteriaand moss-dominated crusts, respectively $(t$ test, $t=1.1, P=$ $0.32, \mathrm{~d} f=1)$. Eukaryotic community data was based on the recovery of 1232312 quality sequences and 5176 unique OTUs.

\section{Discussion}

In biological networks, the magnitude and direction of resource transfer in fungi is predominantly thought to be influenced by the physiological source-sink gradients created by individual plants (Fellbaum et al., 2014) or between plants (Weremijewicz et al., 2016). However, fungi may prove themselves to be more than just passive conduits by exerting control over resources due to their own source-sink resource needs (Simard and Durall, 2004). Our findings suggest that a minor, localized rainfall event may initiate fungal loops by allowing the rapid translocation of $\mathrm{N}$ in biocrusts at a rate of $40 \mathrm{~mm} \mathrm{~h}^{-1}$ in $24 \mathrm{~h}$. The movement of $\mathrm{N}$ was only apparent in the cyanobacteria-dominated crusts, where $\delta^{15} \mathrm{~N}$ decreased as the distance from the addition of the ${ }^{15} \mathrm{NH}_{4}^{+}$ label increased. Further, the presence of Ascomycota was related to the amount of biocrust $\delta^{15} \mathrm{~N}$ from ${ }^{15} \mathrm{NH}_{4}^{+}$, with the isotope being diluted in soils with higher levels of Ascomycota biomass. Eighty-three percent of the Ascomycota were

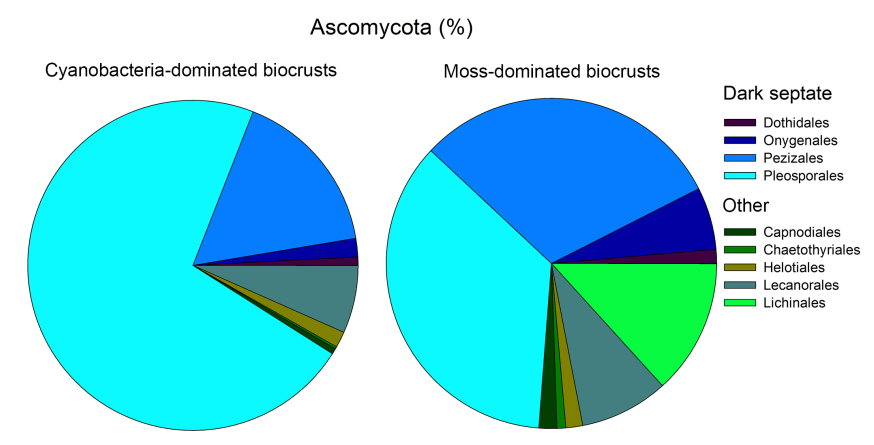

Figure 3. Pleosporales was the dominant Ascomycota order and contained dark septate species. Pie chart values are means $(n=6)$ of the percent relative recovery from nine fungal orders, four of which contain dark septate endophytic taxa. Recovery was based on OTUs from eukaryotic community libraries of the 18S rRNA gene $(97 \%$ similarity cutoff).

from four fungal orders containing known dark septate endophytes and $66 \%$ of these taxa were from one order, the Pleosporales. Taken together, our results suggest that fungal loops are potentially structured by fungal constituents, especially Pleosporales, translocating $\mathrm{N}$ from $\mathrm{NH}_{4}^{+}$over $\mathrm{NO}_{3}^{-}$.

\subsection{Fungal loops only in cyanobacteria-dominated crusts}

Our findings suggest that fungal loops do occur in cyanobacteria-dominated biocrusts. Biocrust components, predominantly cyanobacteria, are known to fix and secrete up to $50 \%$ of their newly fixed $\mathrm{C}$ and $88 \%$ of $\mathrm{N}$ into surrounding soils within minutes to days of fixation, depending on precipitation characteristics (Belnap et al., 2003). Thus, active crust constituents may exude resources for other biocrust constituents, such as fungi, to acquire and initiate fungal loops. Our results are similar to Green et al. (2008) whose previous work identified loops in cyanobacteria biocrusts moving ${ }^{15} \mathrm{~N}$ from isotopically labeled nitrate in the Chihuahuan Desert. Although we only found movement of ${ }^{15} \mathrm{~N}$ as labeled ammonium, our label moved at a comparable rate to Green et al. (2008; $40 \mathrm{~mm} \mathrm{~h}^{-1}$ vs. $44 \mathrm{~mm} \mathrm{~h}^{-1}$, respectively). The lack of ${ }^{15} \mathrm{~N}$ movement from labeled nitrate in our study may stem from the short time period that we employed to measure translocation. When Green et al. (2008) evaluated ${ }^{15} \mathrm{~N}$ movement at two time points, $24 \mathrm{~h}$ and 4 days after tracer application, they found that biocrust enrichment consistently increased over time. Therefore, if we had continued to assess biocrusts isotopic signatures after $24 \mathrm{~h}$, we potentially could have captured the movement of labeled nitrate as well.

\subsection{Addressing the lack of loops in moss-dominated crusts}

The seeming lack of loops in moss-dominated crusts may stem from the relatively large moss biomass of $S$. canin- 
ervis effectively absorbing and holding $\mathrm{N}$ from our minor wet deposition event. We measured elevated levels of biomass of all biocrust constituents (i.e., mosses, fungi, and bacteria) in moss-dominated relative to cyanobacteria-dominated biocrusts. If most biocrust constituents were $\mathrm{N}$ limited, including mosses, then the ${ }^{15} \mathrm{~N}$ was possibly retained in place to meet $\mathrm{N}$ deficiencies before being disseminated to other crust constituents outside the application zone. The ability of mosses to scavenge atmospheric deposited $\mathrm{N}$ is well recognized in other systems (Liu et al., 2013; Fritz et al., 2014). Most mosses acquire $\mathrm{N}$ from either wet/dry atmospheric deposition (Yuanming et al., 2016) or as biogenic sources from cyanobacterial associations on their leaves (Rousk et al., 2013). Mosses do alter $\mathrm{N}$ dynamics in arid environments. When $S$. caninervis was lost from our system, a dramatic increase in nitrification rates were observed (Reed et al., 2012). The higher levels of nitrification were most likely supported by the decomposition of dead moss biomass and the subsequent release of new $\mathrm{NH}_{4}^{+}$; however, after the moss mortality, inorganic $\mathrm{N}$ pooled as $\mathrm{NO}_{3}^{-}$, in the remaining cyanobacteriadominated biocrust. Thus, the presence or absence of mosses has the potential to alter $\mathrm{N}$ pools and fluxes in biocrusts.

The lack of ${ }^{15} \mathrm{~N}$ movement in moss-dominated crusts may stem from the nature of our minor rainfall event. Our moss, S. caninervis, became photosynthetically active following the $2 \mathrm{~mm}$ rainfall event, changing in color from brown to green, but only in the discrete biocrust patches that we watered. Mosses, including $S$. caninervis, are stimulated by minor rainfall events (Wu et al., 2014), with events as small as $1 \mathrm{~mm}$ activating moss photosynthesis (Coe et al., 2012). Our rainfall event was intended to wet a small circle of biocrust to a depth of $1 \mathrm{~cm}$. However, the additional aboveground biomass of mosses and the rugose topography of moss-dominated crusts relative to the smooth cyanobacteria-dominated crusts may have limited the depth our minor rainfall event penetrated the soil and, in turn, activated other biocrust components. Also, water from our event might have evaporated more quickly from the mossy biocrust surface, limiting the activity time of all constituents involved. To more conclusively determine the potential for fungal loops to exist in moss-dominated biocrusts, more information is needed to determine the importance of effective rainfall size in initiating fungal loops.

$\mathrm{N}$ may move differently in moss-dominated biocrusts compared to other biocrust types. If desert mosses have fungal associations, then fungi have the potential to move sequestered $\mathrm{N}$ to the mosses in a new kind of loop. Rhizoids and thalli of bryophytes may contain fungal associations (Pressel et al., 2010). Dark septate endophytes colonize mosses (Day and Currah, 2011). Taken together, the exchange of photosynthate and $\mathrm{N}$ may occur in a tighter, more localized loop between mosses and dark septate fungi, even following a minor rainfall event.

\subsection{Loops may preferentially move $\mathrm{NH}_{4}^{+}$over $\mathrm{NO}_{3}^{-}$}

We found that $\mathrm{NH}_{4}^{+}$, but not $\mathrm{NO}_{3}^{-}$, was rapidly translocated within cyanobacterial crusts. The enrichment of $\delta^{15} \mathrm{~N}$ from ${ }^{15} \mathrm{NH}_{4}^{+}$in cyanobacteria biocrusts was related to our proxy for Ascomycota biomass and potentially dark septate fungi due to their dominance in our sequencing effort. We explain the negative relationship between Ascomycota gene copy number and $\delta^{15} \mathrm{~N}$ signal as a simple dilution - the higher our biomass estimates of Ascomycota, the more spread in the ${ }^{15} \mathrm{~N}$ signal. Although the physiology of dark septate fungi remains relatively unexplored, if our desert fungi are like most other fungi, then the preferential movement of $\mathrm{NH}_{4}^{+}$is understandable. Generally, fungi prefer $\mathrm{NH}_{4}^{+}$over $\mathrm{NO}_{3}^{-}$(Eltrop and Marschner, 1996), as $\mathrm{NH}_{4}^{+}$is readily acquired by fungi and assimilated into amino acids. After $\mathrm{NH}_{4}^{+}$uptake and assimilation via the glutamate synthase (GS/GOGAT) cycle, $\mathrm{N}$ is incorporated into arginine through the urea cycle (Jin et al., 2012) due to the direct assimilation of $\mathrm{NH}_{4}^{+}$into the GS/GOGAT pathway (Geisseler et al., 2010). Thus, $\mathrm{NH}_{4}^{+}$ is most likely transformed into arginine and moved within mycelium by amino acid transporters (Govindarajulu et al., 2005; Garcia et al., 2016). There is some evidence for the importance of amino acid transporters in fungal endophytes, as arbuscular colonization leads to an increase in the uptake of arginine and multiple other amino acids (e.g., phenylalanine, lysine, asparagine, histidine, methionine, tryptophan, and cysteine) by their host plants (Whiteside et al., 2012). However, to verify the movement of $\mathrm{N}$ through Ascomycota and the role of biomass in translocation, a more direct approach is needed. For example, quantum dots (fluorescent nanoscale semiconductors) have tracked the flow of organically derived $\mathrm{N}$ into arbuscular mycorrhizae and into Poa апnиa in less than $24 \mathrm{~h}$ (Whiteside et al., 2009). The $\mathrm{N}$ form $\mathrm{NO}_{3}^{-}$did move into our cyanobacteria crusts but not nearly to the extent reported by Green et al. (2008). Besides fungal preferences, other factors may play a role in the uptake of $\mathrm{N}$, such as the increase in mobility of $\mathrm{NO}_{3}^{-}$in soils, differences in soil cation exchange capacity due to clay content, or fungi capitalizing on the more abundant $\mathrm{N}$ form specific to a soil. Unfortunately, based on our design, we were unable to distinguish the form of $\mathrm{N}$ captured or translocated by biocrust constituents. More information is needed to identify the importance of $\mathrm{N}$ form and the movement of organic $\mathrm{N}$ within fungal loops.

\subsection{Dark septate and Pleosporales as conduits}

Our results support the idea that Pleosporales are the most likely conduits for N. Four of the nine fungal orders we identified contained known dark septate endophytes with one order, Pleosporales, being the most abundant. Pleosporales accounted for $66 \%$ of the Ascomycota taxa in cyanobacteria crusts. Based on the relationship between $\delta^{15} \mathrm{~N}$ and Ascomycota biomass, the overwhelming abundance of Pleosporales, 
and the universal occurrence of Ascomycota in biocrusts, the Pleosporales assumedly play a role in fungal loops. We are not the first to reach this conclusion. Green et al. (2008) also identified Pleosporales as being the primary candidate involved in fungal loops. In their semi-arid grassland, Pleosporales were the most common taxa on Bouteloua roots, in the rhizosphere, and in biocrusts. We found 799 operational taxonomic units, based on $97 \%$ similarity, with all of the identifiable sequences, belonging to three genera: Leptosphaeria (1.6\% of Pleosporales sequences), Morosphaeria (3.8\% of Pleosporales sequences), and Ophiosphaerella (8.1\% of Pleosporales sequences; data not shown). Leptosphaeria and Ophiosphaerella may be pathogenic endophytes on grass species (Martin et al., 2001; Yuan et al., 2017), but may also be beneficial by delaying and reducing the symptoms of other fungal pathogens (Yuan et al., 2017). However, $86 \%$ of our Pleosporales taxa were unidentifiable based on our target genetic region and are potentially novel, suggesting that much remains unknown about dark septates in deserts. Further research is needed to address the theory of Pleosporales conduits in biocrusts and the ecological importance of the dark septate endophytes in desert systems.

\subsection{Little $N$ translocation to grass}

Due to the discrete nature of our minor, localized rainfall event, we were not surprised that little of the label entered the leaves of A. hymenoides. In the fungal loop hypothesis, a larger rainfall event triggers the plant to become a sink for the $\mathrm{N}$ building up in fungi over previous minor rainfall events. We conducted our experiment without a larger rainfall event and our $2.5 \mathrm{~mm}$ rainfall event was applied over a $5 \mathrm{~cm}$ diameter circle of soil in early summer. When a similar precipitation event size $(2 \mathrm{~mm})$ was applied across a much larger area $\left(4 \times 4 \mathrm{~m}^{2}\right.$ plot) on Colorado Plateau soils during spring or summer, the predawn water potential of $A$. hymenoides was similar one day after and one day prior to watering (Schwinning et al., 2003). Thus, our minor rainfall event most likely failed to alter the water status of the grass or cause grasses to become a sink for N. However, we did find some evidence of ${ }^{15} \mathrm{~N}$ in A. hymenoides leaves following our ${ }^{15} \mathrm{NH}_{4}^{+}$application in cyanobacteria-dominated crusts. The pattern of the enrichment, which was a dilution with increasing distance from the application point, was similar to the pattern found in biocrusts, but the most enriched leaves $(6.7 \%$ ) were less than the least enriched crust $(9.1 \%$ ). Even though the enrichment was minor, the presence of ${ }^{15} \mathrm{~N}$ in A. hymenoides provides some evidence of biocrust constituents being linked to plants and the translocation of $\mathrm{N}$ occurring even in the absence of a larger rainfall event to enhance grass activity. In April, at the time of the experiment, A. hymenoides was photosynthetically active. If we had added more label or evaluated the isotope signature of roots, we may have detected more ${ }^{15} \mathrm{~N}$ label in grass tissue.

\section{Conclusions}

Cyanobacterial biocrusts are potentially interconnected in extensive biological networks. In light of the absence of $\mathrm{N}$ movement in moss-dominated crusts, mosses may hinder fungal loops. The abundant moss biomass in some biocrust may absorb and retain the applied $\mathrm{N}$ label. Due to the dominance of dark septate endophytes in biocrusts, fungi may act as conduits within the network. Our results add to the indirect evidence of fungal loops; however more information is needed to quantify the environmental conditions and biocrust constituents controlling the magnitude and directionality of the translocation of $\mathrm{N}$ to vascular plants.

Data availability. All sequence data were submitted to NCBI and are available as BioProject PRJNA476977.

Supplement. The supplement related to this article is available online at: https://doi.org/10.5194/bg-15-3831-2018-supplement.

Author contributions. ZTA and JB designed the study. ZTA, TBS, NW, AST, and JB conducted the experiments. ZTA, TBS, NW, AST, YZ, and JB analyzed and interpreted the data. ZTA, TBS, NW, AST, $\mathrm{YZ}$, and JB helped write and review the manuscript. ZTA agrees to be accountable for all aspects of the work in ensuring that questions related to the accuracy or integrity of any part of the work are appropriately investigated and resolved.

Competing interests. The authors declare that they have no conflict of interest.

Special issue statement. This article is part of the special issue " $\mathrm{Bi}$ ological soil crusts and their role in biogeochemical processes and cycling". It is a result of the BIOCRUST3 conference, Moab, USA, 26 to 30 September 2016.

Acknowledgements. The portion of the research conducted by Nan $\mathrm{Wu}$ and Yuanming Zhang was funded by the National Natural Science Foundation of China (grant numbers 41571256 and 41771299). Belnap thanks the Ecosystems Program of the US Geological Survey. Any use of trade, firm, or product names is for descriptive purposes only and does not imply endorsement by the US Government.

Edited by: Emilio Rodriguez-Caballero

Reviewed by: Trent Northen and one anonymous referee 


\section{References}

Aanderud, Z. T., Jones, S. E., Schoolmaster, D. R., Fierer, N., and Lennon, J. T.: Sensitivity of soil respiration and microbial communities to altered snowfall, Soil Biol. Biochem., 57, 217-227, 2013.

Aguilera, L. E., Armas, C., Cea, A. P., Gutierrez, J. R., Meserve, P. L., and Kelt, D. A.: Rainfall, microhabitat, and small mammals influence the abundance and distribution of soil microorganisms in a Chilean semi-arid shrubland, J. Arid. Environ., 126, 37-46, 2016

Amaral-Zettler, L. A., McCliment, E. A., Ducklow, H. W., and Huse, S. M.: A method for studying protistan diversity using massively parallel sequencing of V9 hypervariable regions of small-subunit ribosomal RNA genes, PLOS ONE, 4, e6372, https://doi.org/10.1371/journal.pone.0006372, 2009.

Aronesty, E.: Command-line tools for processing biological sequence data, Expression Analysis, available at: https://github. com/ExpressionAnalysis/ea-utils (last access: 14 October 2017), 2011.

Barrow, J. R.: Atypical morphology of dark septate fungal root endophytes of Bouteloua in arid southwestern USA rangelands, Mycorrhiza, 13, 239-247, 2003.

Bates, S. T., Nash, T. H., and Garcia-Pichel, F.: Patterns of diversity for fungal assemblages of biological soil crusts from the southwestern United States, Mycologia, 104, 353-361, 2012.

Behie, S. W. and Bidochka, M. J.: Nutrient transfer in plant-fungal symbioses, Trends Plant. Sci., 19, 734-740, 2014

Belnap, J., Hawkes, C. V., and Firestone, M. K.: Boundaries in miniature: Two examples from soil, BioScience, 53, 739-749, 2003.

Belnap, J., Phillips, S. L., Sherrod, S. K., and Moldenke, A.: Soil biota can change after exotic plant invasion: does this affect ecosystem processes?, Ecology, 86, 3007-3017, 2005.

Benjamini, Y. and Hochberg, Y.: Controlling the false discovery rate: a practical and powerful approach to multiple testing, J. Roy. Stat. Soc. B. Met., 57, 289-300, 1995.

Cable, J. M. and Huxman, T. E.: Precipitation pulse size effects on Sonoran Desert soil microbial crusts, Oecologia, 141, 317-324, 2004.

Caporaso, J. G., Kuczynski, J., Stombaugh, J., Bittinger, K., Bushman, F. D., Costello, E. K., Fierer, N., Peña, A. G., Goodrich, J. K., Gordon, J. I., Huttley, G. A., Kelley, S. T., Knights, D., Koenig, J. E., Ley, R. E., Lozupone, C. A., McDonald, D., Muegge, B. D., Pirrung, M., Reeder, J., Sevinsky, J. R., Turnbaugh, P. J., Walters, W. A., Widmann, J., Yatsunenko, T., Zaneveld, J., and Knight, R.: QIIME allows analysis of highthroughput community sequencing data, Nat. Methods, 7, 335336, 2010.

Coe, K. K., Belnap, J., and Sparks, J. P.: Precipitation-driven carbon balance controls survivorship of desert biocrust mosses, Ecology, 93, 1626-1636, 2012.

Collins, S. L., Sinsabaugh, R. L., Crenshaw, C., Green, L., PorrasAlfaro, A., Stursova, M., and Zeglin, L. H.: Pulse dynamics and microbial processes in aridland ecosystems, J. Ecol., 96, 413420, 2008

Collins, S. L., Belnap, J., Grimm, N. B., Rudgers, J. A., Dahm, C. N., D’Odorico, P., Litvak, M., Natvig, D. O., Peters, D. C., Pockman, W. T., Sinsabaugh, R. L., and Wolf, B. O.: A multiscale, hierarchical model of pulse dynamics in arid-land ecosystems, Annu. Rev. Ecol. Evol. S., 45, 397-419, 2014.

Darrouzet-Nardi, A., Reed, S. C., Grote, E. E., and Belnap, J.: Observations of net soil exchange of $\mathrm{CO}_{2}$ in a dryland show experimental warming increases carbon losses in biocrust soils, Biogeochemistry, 126, 363-378, 2015.

Day, M. J. and Currah, R. S.: Role of selected dark septate endophyte species and other hyphomycetes as saprobes on moss gametophytes, Botany, 89, 349-359, 2011.

Edgar, R. C., Haas, B. J., Clemente, J. C., Quince, C., and Knight, R.: UCHIME improves sensitivity and speed of chimera detection, Bioinformatics, 27, 2194-2200, 2011.

Eltrop, L. and Marschner, H.: Growth and mineral nutrition of non-mycorrhizal and mycorrhizal Norway spruce (Picea abies) seedlings grown in semi-hydroponic sand culture, New Phytol., 133, 469-478, 1996.

Fellbaum, C. R., Mensah, J. A., Cloos, A. J., Strahan, G. E., Pfeffer, P. E., Kiers, E. T., and Bucking, H: Fungal nutrient allocation in common mycorrhizal networks is regulated by the carbon source strength of individual host plants, New Phytol., 203, 646-656, 2014.

Fierer, N., Jackson, J. A., Vilgalys, R., and Jackson, R. B.: Assessment of soil microbial community structure by use of taxonspecific quantitative PCR assays, Appl. Environ. Microb., 71, 4117-4120, 2005.

Fritz, C., Lamers, L. P. M., Riaz, M., van den Berg, L. J. L., and Elzenga, T.: Sphagnum mosses-masters of efficient $\mathrm{N}$ uptake while avoiding intoxication, PLOS ONE, 9, e79991, https://doi.org/10.1371/journal.pone.0079991, 2014.

Garcia, K., Doidy, J., Zimmermann, S. D., Wipf, D., and Courty, P. E.: Take a trip through the plant and fungal transportome of mycorrhiza, Trends Plant. Sci., 21, 937-950, 2016.

Geisseler, D., Horwath, W. R., Joergensen, R. G., and Ludwig, B: Pathways of nitrogen utilization by soil microorganisms - A review, Soil. Biol. Biochem., 42, 2058-2067, 2010.

Gostincar, C., Grube, M., de Hoog, S., Zalar, P., and GundeCimerman, N.: Extremotolerance in fungi: evolution on the edge, FEMS Microbiol. Ecol., 71, 2-11, 2010.

Govindarajulu, M., Pfeffer, P. E., Jin, H. R., Abubaker, J., Douds, D. D., Allen, J. W., Bucking, H., Lammers, P. J., and Shachar-Hill, Y.: Nitrogen transfer in the arbuscular mycorrhizal symbiosis, Nature, 435, 819-823, 2005.

Green, L. E., Porras-Alfaro, A., and Sinsabaugh, R. L.: Translocation of nitrogen and carbon integrates biotic crust and grass production in desert grassland, J. Ecol., 96, 1076-1085, 2008.

Haas, B. J., Gevers, D., Earl, A. M., Feldgarden, M., Ward, D. V., Giannoukos, G., Ciulla, D., Tabbaa, D., Highlander, S. K., Sodergren, E., Methe, B., DeSantis, T. Z., The Human Microbiome Consortium, Petrosino, J. F., Knight, R., and Birren, B. W.: Chimeric 16S rRNA sequence formation and detection in Sanger and 454-pyrosequenced PCR amplicons, Biotechfor., 21, 494-504, 2011.

Hamady, M., Walker, J. J., Harris, J. K., Gold, N. J., and Knight, R.: Error-correcting barcoded primers for pyrosequencing hundreds of samples in multiplex, Nat. Methods, 5, 235-237, 2008.

Hattenschwiler, S., Tiunov, A. V., and Scheu, S.: Biodiversity and litter decomposition in terrestrial ecosystems, Annu. Rev. Ecol Evol. S., 36, 191-218, 2005. 
He, X. H., Critchley, C., and Bledsoe, C.: Nitrogen transfer within and between plants through common mycorrhizal networks (CMNs), Crc. Cr. Rev. Plant. Sci., 22, 531-567, 2003.

Huxman, T. E., Snyder, K. A., Tissue, D., Leffler, A. J., Ogle, K., Pockman, W. T., Sandquist, D. R., Potts, D. L., and Schwinning, S.: Precipitation pulses and carbon fluxes in semiarid and arid ecosystems, Oecologia, 141, 254-268, 2004.

Jin, H. R., Liu, J., and Huang, X. W.: Forms of nitrogen uptake, translocation, and transfer via arbuscular mycorrhizal fungi, A review, Sci. China Life Sci., 55, 474-482, 2012.

Johnson, N. C., Graham, J. H., and Smith, F. A.: Functioning of mycorrhizal associations along the mutualism-parasitism continuum, New Phytol., 135, 575-586, 1997.

Jumpponen, A and Trappe, J. M.: Dark septate endophytes: a review of facultative biotrophic root-colonizing fungi, New Phytol., 140, 295-310, 1998.

Larena, I., Salazar, O., Gonzalez, V., Julian, M. C., and Rubio, V.: Design of a primer for ribosomal DNA internal transcribed spacer with enhanced specificity for ascomycetes, J. Biotechnol., 75, 187-194, 1999.

Liu, X. Y., Koba, K., Makabe, A., Li, X. D., Yoh, M., and Liu, C. $\mathrm{Q} .:$ Ammonium first: natural mosses prefer atmospheric ammonium but vary utilization of dissolved organic nitrogen depending on habitat and nitrogen deposition, New Phytol., 199, 407-419, 2013.

Martin, D. L., Bell, G. E., Baird, J. H, Taliaferro, C. M., Tisserat, N. A., Kuzmic, R. M., Dobson, D. D., and Anderson, J. A.: Spring dead spot resistance and quality of seeded bermudagrasses under different mowing heights, Crop. Sci., 41, 451-456, 2001.

Osono, T.: Ecology of ligninolytic fungi associated with leaf litter decomposition, Ecol. Res., 22, 955-974, 2007.

Porras-Alfaro, A., Herrera, J., Natvig, D. O., Lipinski, K., and Sinsabaugh, R. L.: Diversity and distribution of soil fungal communities in a semiarid grassland, Mycologia, 103, 10-21, 2011.

Pressel, S., Bidartondo, M. I., Ligrone, R., and Duckett, J. G.: Fungal symbioses in bryophytes: new insights in the twenty first century, Phytotaxa, 9, 238-253, 2010.

Quast, C., Pruesse, E., Yilmaz, P., Gerken, J., Schweer, T., Yarza, P., Peplies, J., and Glockner, F. O.: The SILVA ribosomal RNA gene database project: improved data processing and web-based tools, Nucleic Acids Res., 41, D590-D596, 2013.

R Development Core Team: R: A language and environment for statistical computing. R Foundation for Statistical Computing, Vienna, Austria, available at: http://www.R-project.org (last access: March 2018), 2017.

Reed, S. C., Coe, K. K., Sparks, J. P., Housman, D. C., Zelikova, T. J., and Belnap, J.: Changes to dryland rainfall result in rapid moss mortality and altered soil fertility, Nat. Clim. Change, 2, 752-755, 2012.

Rousk, K., Jones, D. L., and DeLuca, T. H.: Mosscyanobacteria associations as biogenic sources of nitrogen in boreal forest ecosystems, Front. Microbiol., 4, 150, https://doi.org/10.3389/fmicb.2013.00150, 2013.

Saikkonen, K., Wali, P., Helander, M., and Faeth, S. H.: Evolution of endophyte-plant symbioses, Trends Plant. Sci., 9, 275-280, 2004.

Schneider, T., Keiblinger, K. M., Schmid, E., Sterflinger-Gleixner, K., Ellersdorfer, G., Roschitzki, B., Richter, A., Eberl, L., Zechmeister-Boltenstern, S., and Riedel, K.: Who is who in litter decomposition? Metaproteomics reveals major microbial players and their biogeochemical functions, ISME J., 6, 1749-1762, 2012.

Schwinning, S., Starr, B. L., and Ehleringer, J. R.: Dominant cold desert plants do not partition warm season precipitation by event size, Ecosytems Ecology, 136, 252-260, 2003.

Simard, S. W. and Durall, D. M.: Mycorrhizal networks: a review of their extent, function, and importance, Can. J. Botany, 82, 11401165, 2004.

Sperry, L. J., Belnap, J., and Evans, R. D.: Bromus tectorum invasion alters nitrogen dynamics in an undisturbed arid grassland ecosystem, Ecology, 87, 603-615, 2006.

Titus, J. H., Titus, P. J., Nowak, R. S., and Smith, S. D.: Arbuscular mycorrhizae of Mojave Desert plants, West. N. Am. Naturalist, 62, 327-334, 2002.

van der Heijden, M. G. A. and Horton, T. R.: Socialism in soil? The importance of mycorrhizal fungal networks for facilitation in natural ecosystems, J. Ecol., 97, 1139-1150, 2009.

Walder, F., Niemann, H., Natarajan, M., Lehmann, M. F., Boller, T., and Wiemken, A.: Mycorrhizal networks: common goods of plants shared under unequal terms of trade, Plant Physiol., 159, 789-797, 2012.

Wang, C., Wang, X., Liu, D., Wu, H., Lu, X., Fang, Y., Cheng, W., Luo, W., Jiang, P., Shi, J., Yin, H., Zhou, J., Han, X., and Bai, E.: Aridity threshold in controlling ecosystem nitrogen cycling in arid and semi-arid grasslands, Nat. Commun., 5, 4799, https://doi.org/10.1038/ncomms5799 2014.

Welter, J. R., Fisher, S. G., and Grimm, N. B.: Nitrogen transport and retention in an arid land watershed: Influence of storm characteristics on terrestrial-aquatic linkages, Biogeochemistry, 76, 421-440, 2005.

Weremijewicz, J., Sternberg, L., and Janos, D. P.: Common mycorrhizal networks amplify competition by preferential mineral nutrient allocation to large host plants, New Phytol., 212, 461-471, 2016.

Whiteside, M. D., Treseder, K. K., and Atsatt, P. R.: The brighter side of soils: quantum dots track organic nitrogen through fungi and plants, Ecology, 90, 100-108, 2009.

Whiteside, M. D., Garcia, M. O., and Treseder, K. K.: Amino Acid Uptake in Arbuscular Mycorrhizal Plants, PLOS ONE, 7, e47643, https://doi.org/10.1371/journal.pone.0047643, 2012.

Wu, N., Zhang, Y. M., Downing, A., Aanderud, Z. T., Tao, Y., and Williams, S.: Rapid adjustment of leaf angle explains how the desert moss, Syntrichia caninervis, copes with multiple resource limitations during rehydration, Funct. Plant. Biol., 41, 168-177, 2014.

Yahdjian, L. and Sala, O. E.: Size of precipitation pulses controls nitrogen transformation and losses in an arid Patagonian ecosystem, Ecosystems, 13, 575-585, 2010.

Yuanming, Z., Xiaobing, Z., Benfeng, Y., and Downing, A.:Sensitivity of moss Synthrichia caninervis to prolonged simulated nitrogen deposition, Ann. Bot.-London, 117, 1153-1161, https://doi.org/10.1093/aob/mcw058, 2016.

Yuan, Y., Feng, H. J., Wang, L. F., Li, Z. F., Shi, Y. Q., Zhao, L. H., Feng, Z. L., and Zhu, H. Q.: Potential of endophytic fungi isolated from cotton roots for biological control against verticillium wilt disease, PLOS ONE, 12, e0170557, https://doi.org/10.1371/journal.pone.0170557, 2017. 